\title{
$15 \mathrm{~Gb} / \mathrm{s}$ index-coupled distributed-feedback lasers based on $1.3 \mu \mathrm{m}$ InGaAs quantum dots
}

Cite as: Appl. Phys. Lett. 105, 011103 (2014); https://doi.org/10.1063/1.4887063

Submitted: 05 June 2014 • Accepted: 24 June 2014 • Published Online: 07 July 2014

M. Stubenrauch, G. Stracke, D. Arsenijević, et al.
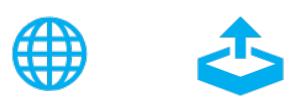

View Online

Export Citation

\section{ARTICLES YOU MAY BE INTERESTED IN}

Comparison of dynamic properties of ground- and excited-state emission in p-doped InAs/ GaAs quantum-dot lasers

Applied Physics Letters 104, 181101 (2014); https://doi.org/10.1063/1.4875238

Perspective: The future of quantum dot photonic integrated circuits

APL Photonics 3, 030901 (2018); https://doi.org/10.1063/1.5021345

Multidimensional quantum well laser and temperature dependence of its threshold current Applied Physics Letters 40, 939 (1982); https://doi.org/10.1063/1.92959

耳QBLOX

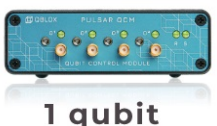

Shorten Setup Time Auto-Calibration More Qubits

Fully-integrated Quantum Control Stacks Ultrastable DC to $18.5 \mathrm{GHz}$ Synchronized $<<1$ ns Ultralow noise

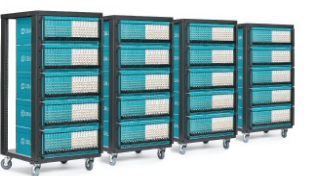

100s qubits

visit our website > 


\title{
$15 \mathrm{~Gb} / \mathrm{s}$ index-coupled distributed-feedback lasers based on $1.3 \mu \mathrm{m}$ InGaAs quantum dots
}

\author{
M. Stubenrauch, ${ }^{1, a)}$ G. Stracke, ${ }^{1}$ D. Arsenijević, ${ }^{1}$ A. Strittmatter, ${ }^{2}$ and D. Bimberg ${ }^{1}$ \\ ${ }^{1}$ Institut für Festkörperphysik, Technische Universität Berlin, Hardenbergstr. 36, 10623 Berlin, Germany \\ ${ }^{2}$ Institut für Experimentelle Physik, Otto-von-Guericke-Universität Magdeburg, Universitätsplatz 2, \\ 39106 Magdeburg, Germany
}

(Received 5 June 2014; accepted 24 June 2014; published online 7 July 2014)

\begin{abstract}
The static properties and large-signal modulation capabilities of directly modulated p-doped quantum-dot distributed-feedback lasers are presented. Based on pure index gratings the devices exhibit a side-mode-suppression ratio of $58 \mathrm{~dB}$ and optical output powers up to $34 \mathrm{~mW}$. Assisted by a broad gain spectrum, which is typical for quantum-dot material, emission wavelengths from $1290 \mathrm{~nm}$ to $1310 \mathrm{~nm}$ are covered by the transversal and longitudinal single-mode lasers fabricated from the same single wafer. Thus, these lasers are ideal devices for on-chip wavelength division multiplexing within the original-band according to the IEEE802.3ba standard. $10 \mathrm{~Gb} / \mathrm{s}$ data transmission across $30 \mathrm{~km}$ of single mode fiber is demonstrated. The maximum error-free data rate is found to be $15 \mathrm{~Gb} / \mathrm{s}$. (C) 2014 AIP Publishing LLC. [http://dx.doi.org/10.1063/1.4887063]
\end{abstract}

Distributed-feedback (DFB) lasers are key devices for modern optical data communication systems. DFB lasers provide longitudinal single mode emission with a narrow line width, making them indispensable for dense wavelength division multiplexing (WDM) systems. ${ }^{1,2}$ DFB lasers based on quantum dots (QDs) benefit from the same unique properties already demonstrated for ridge-waveguide edge-emitting QD lasers like high temperature stability, ${ }^{3,4}$ low feedback sensitivity, ${ }^{5}$ low chirp, ${ }^{6}$ and low internal losses. ${ }^{7,8}$ Their potential for high-speed data communication under direct modulation up to $25 \mathrm{~Gb} / \mathrm{s}$ by means of excited state lasing was recently shown. ${ }^{9}$ The typical size distribution of self-organized QDs results in a wide gain spectrum that ensures a broad distribution of target emission wavelengths and a higher insensitivity to temperature or charge carrier induced gain spectrum shifts. ${ }^{10}$ High-speed characteristics and temperature stability of the threshold current of QD lasers is improved by p-doping of the active region. ${ }^{11}$ Within the last years, several groups $^{12-16}$ have developed alternative concepts to realize QD DFB lasers. Since QDs can degrade at high growth temperatures, induced by indium depletion, the common technique of quantum-well (QW) DFB laser fabrication using an overgrowth step was avoided by implementation of lateral metal gratings. Such laterally-loss-coupled (LLC) DFB lasers feature proper static characteristics, like side-mode suppression ratio (SMSR) up to $50 \mathrm{~dB}$ and slope efficiencies in the range of $0.15 \mathrm{~W} / \mathrm{A}^{12}$ In Ref. 13, modulation of single DFB lasers at $10 \mathrm{~Gb} / \mathrm{s}$ was demonstrated, showing a SMSR up to $55 \mathrm{~dB}$ and a slope efficiency of $0.14 \mathrm{~W} / \mathrm{A}$. However, loss coupling reduces the photon life time in the effective cavity. Consequently, highly reflective facets are necessary, which complicates the monolithic integration with other devices. Moreover, the span of single-mode lasing can be limited, i.e., Fabry-Perot (FP) ground- or excited-state lasing can occur by changing operation parameters. Pure index-coupling was attempted by etching the grating vertically into the deep

a)mirko.stubenrauch@tu-berlin.de etched ridge, but due to large waveguide losses low slope efficiencies below $0.03 \mathrm{~W} / \mathrm{A}$ as well as small SMSR of $20 \mathrm{~dB}$ are observed for lasers driven with pulsed currents. ${ }^{14}$ Most recently, index-coupling with buried gratings was presented, comprising two growth steps: molecular beam epitaxy (MBE) and metal organic vapor chemical deposition epitaxy (MOCVD). At moderate temperatures an AlGaAs upper cladding were grown, accepting changes in grating form and a QD photoluminescence shift to shorter wavelengths. ${ }^{15}$ Their devices achieved $40 \mathrm{~dB}$ SMSR and a slope efficiency of $0.25 \mathrm{~W} / \mathrm{A}$ within a limited operation range. Substituting the upper cladding by $\mathrm{InGaP}$ has led to improved slope efficiency of $0.30 \mathrm{~W} / \mathrm{A}$, a $45 \mathrm{~dB}$ SMSR, and open eyes at $10 \mathrm{~Gb} / \mathrm{s}{ }^{16}$ Index gratings with high index contrast, superseding losscoupled metal gratings, in combination with sufficiently large modal gain render highly reflecting mirrors unnecessary. Such InAs/GaAs-based QD DFB lasers enable monolithic integration, e.g., with electro-absorption modulators (EMLs) as low cost solutions for access networks. ${ }^{17}$ Nevertheless, the direct modulation of QD DFB lasers did not exceed bit rates of $10 \mathrm{~Gb} / \mathrm{s}$ so far. In this paper, we demonstrate a p-doped index-coupled QD DFB lasers for optical data communication at $1.31 \mu \mathrm{m}$ showing largely improved static (increase of SMSR, slope efficiency, and output power) and dynamic properties, demonstrating operation at $15 \mathrm{~Gb} / \mathrm{s}$.

The laser structure is grown on a p-type GaAs substrate by a two-step MBE and MOCVD process. The p-doped $\mathrm{Al}_{0.35} \mathrm{Ga}_{0.65} \mathrm{As}$ bottom cladding and the active region are grown by MBE. The GaAs waveguide contains 15 stacked InAs QD layers, buried in an InGaAs dot-in-a-well structure (DWELL) $)^{18,19}$ to achieve a photoluminescence wavelength close to $1.3 \mu \mathrm{m}$. To compensate the red shift of QD gain spectra during operation, the PL spectra are optimized to be $15 \mathrm{~nm}$ below the target lasing wavelength. For higher threshold temperature stability and faster modulation dynamics, the $33 \mathrm{~nm}$ strain relaxation spacer layers between the QD layers are p-doped with a density of $5 \times 10^{17} \mathrm{~cm}^{-3} \cdot{ }^{11,20} \mathrm{Next}$ to the waveguide, a $150 \mathrm{~nm} \mathrm{InGaP} \mathrm{barrier} \mathrm{layer} \mathrm{and} \mathrm{a}$ 

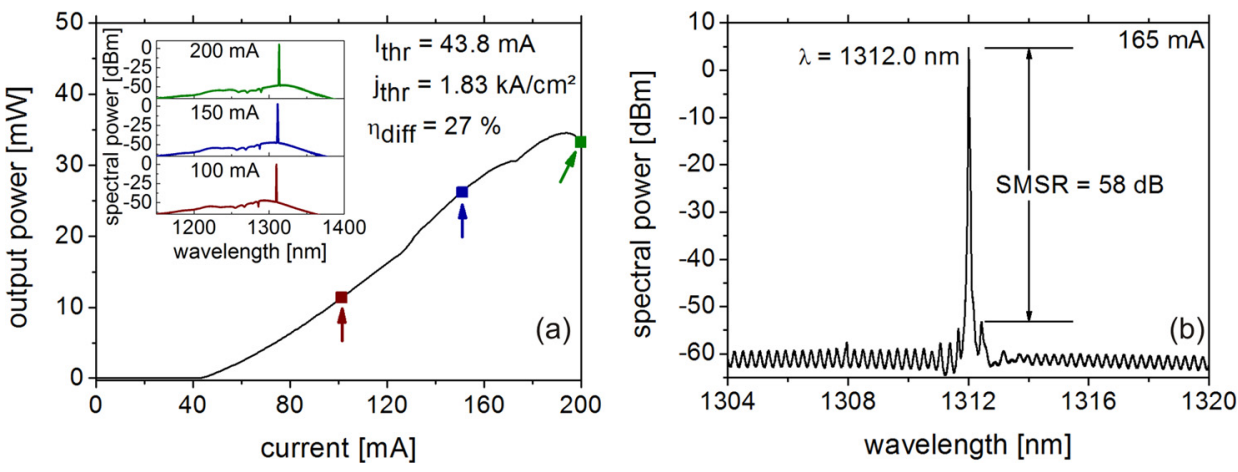

FIG. 1. Power-current characteristics of an $800 \mu \mathrm{m}$ long QD DFB laser at room temperature (a). The inset shows the corresponding optical spectra with longitudinal single-mode emission at $100 \mathrm{~mA}, 150 \mathrm{~mA}$, and $200 \mathrm{~mA}$. A highresolution optical spectrum of the DFB emission line at $165 \mathrm{~mA}$ (b).
$100 \mathrm{~nm}$ GaAs DFB grating layer is grown. The barrier layer reduces the overlap of the guided mode with the grating to achieve a target coupling-length-coefficient of $\kappa \mathrm{L}=2$ for a $800 \mu \mathrm{m}$ long laser, avoiding strong nonlinearity effects in the cavity, like spatial hole burning. ${ }^{21}$ The index grating is fabricated by means of inductive-coupled plasma reactive ion etching (ICP-RIE) and electron beam lithography forming the SiNx mask. Simulations of the final structure considering the effective refraction index of the guided mode lead to grating periods of $192 \mathrm{~nm}$ to $195 \mathrm{~nm}$ for emission at O-band wavelengths. During the MOCVD growth step, the upper nInGaP cladding and a highly n-doped GaAs contact layer are deposited. The advantages of using InGaP, instead of the more common AlGaAs upper cladding, is twofold: an increased refractive index difference to GaAs, and reduced impurity incorporation at low growth temperatures, necessary to suppress QD degradation. Due to the differences of the claddings and the resulting deformation of the guided mode we shifted the QD layers slightly away from the center of the waveguide. $3 \mu \mathrm{m}$ wide and deep etched ridges are defined by standard photo lithography using ICP-RIE to achieve transversal single-mode operation. To reduce electrical parasitic capacitances and allow high-speed operation the structure is planarized with Benzocyclobutene and both contacts are placed on the top. ${ }^{22}$ For ridge n-metallization Ni/ $\mathrm{AuGe} / \mathrm{Au}$ and for $\mathrm{p}$-contacts $\mathrm{Ni} / \mathrm{Zn} / \mathrm{Au}$ are deposited in a high-speed ground-signal-ground configuration. After thinning, backside metallization, and cleaving into $800 \mu \mathrm{m}$ long lasers, the front facet is antireflection $(\mathrm{AR})\left(\mathrm{R}<10^{-4}\right)$ and the rear facet is high reflection coated $(\mathrm{R}=0.98)$ at $1.31 \mathrm{~nm}$.

For static and dynamic characterization the laser is mounted on a temperature controlled copper heat sink at $21^{\circ} \mathrm{C}$. The total optical power is determined by an integrating sphere. For spectral and dynamic measurement, the emission from the AR coated facet was coupled into a standard single-mode fiber (SMF-28). Typical static characteristics of these devices are shown in Figure 1. The power-current curve shows a threshold current of $43.8 \mathrm{~mA}$ corresponding to $1.83 \mathrm{kA} / \mathrm{cm}^{2}$ threshold current density, and a maximum optical output power of about $34 \mathrm{~mW}$. The differential quantum efficiency, derived from a linear fit between $45 \mathrm{~mA}$ and $180 \mathrm{~mA}$, is $27 \%$. The inset shows the corresponding lasing spectra at $100 \mathrm{~mA}, 150 \mathrm{~mA}$, and $200 \mathrm{~mA}$, representative for the whole current range. Longitudinal single-mode operation with suppressed excited-state emission is observed. The spectrum at $165 \mathrm{~mA}$, shown in Fig. 1(b), and taken at the large-signal operation point, shows a DFB lasing mode at $1312.0 \mathrm{~nm}$ and a highly suppressed FP underground leading to a remarkable SMSR of $58 \mathrm{~dB}$. The stop-band is not clearly visible since the structural properties (HR/AR coating, coupling factor, laser length, etc.) of the presented laser lead to a stop-band width that is in the range of the FP-mode spacing and therefore not really distinguishable. The true spectral line width is measured using a self-homodyne technique ${ }^{23}$ and amounts to $6 \mathrm{MHz}$. The laser thus operates longitudinal and transversal $\left(\mathrm{TEM}_{00}\right)$ single mode.

Typical LI characteristics for temperatures from $10^{\circ} \mathrm{C}$ to $55^{\circ} \mathrm{C}$ are shown in Figure 2(a) with threshold currents between $38.3 \mathrm{~mA}$ and $49.5 \mathrm{~mA}$. The reduced temperature sensitivity of threshold current is due to the p-doping of the active region. From $10^{\circ} \mathrm{C}$ to $40^{\circ} \mathrm{C}$, the threshold current density is described by a negative characteristic temperature $\mathrm{T}_{0}$ of $-130 \mathrm{~K}$, followed by a stable region of hardly any temperature dependence (infinite $\mathrm{T}_{0}$ ) up to at least $60^{\circ} \mathrm{C}$. The thermal roll over, induced by the decrease of charge carrier population of the QD ground states, shifts to lower current with the increase of temperature. Since the QD gain has a full width at half maximum of about $80 \mathrm{meV}$, plenty of QD DFB lasers can be fabricated on the same wafer with a variety of grating periods. In Figure 2(b), four DFB lasers
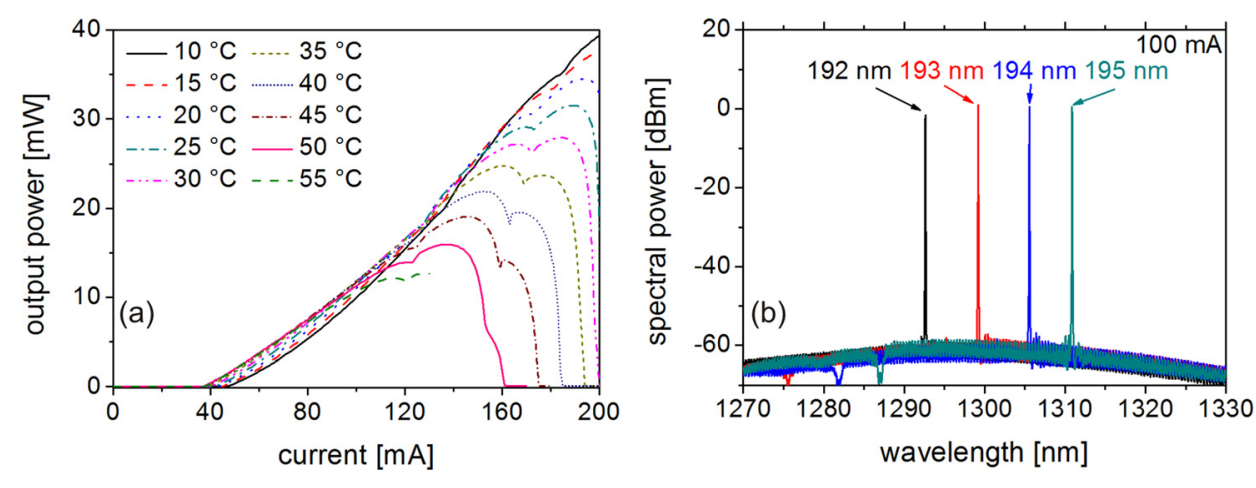

FIG. 2. Power-current characteristics for different heat sink temperatures from $10^{\circ} \mathrm{C}$ to $55^{\circ} \mathrm{C}$ (a). Optical spectra of four QD DFB lasers at $100 \mathrm{~mA}$ with different grating periods from a single wafer (b). 

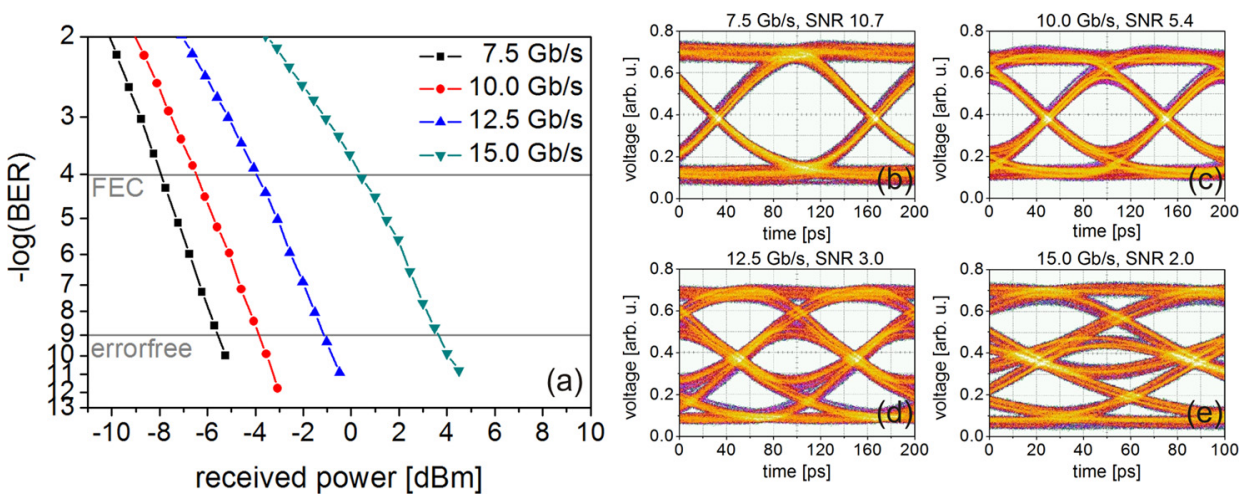

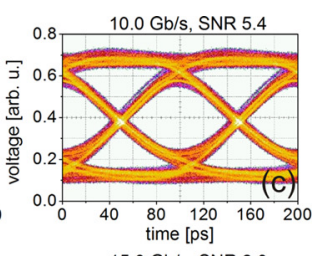

FIG. 3. Bit-error-ratio versus received optical power (a) and corresponding eye diagrams at $7.5 \mathrm{~Gb} / \mathrm{s}(\mathrm{b}), 10 \mathrm{~Gb} / \mathrm{s}$ (c), $12.5 \mathrm{~Gb} / \mathrm{s}$ (d), and $15 \mathrm{~Gb} / \mathrm{s}$ (e). showing about $58 \mathrm{~dB}$ SMSR with emission in the IEEE 802.3 ba specification range from $1290 \mathrm{~nm}$ to $1310 \mathrm{~nm}$ are depicted as examples. From the same wafer, single-mode lasing operation can be observed for a much larger range from $1274 \mathrm{~nm}$ to $1336 \mathrm{~nm}$ (not shown here) with SMSR always larger than $30 \mathrm{~dB}$.

The dynamic large-signal response under direct modulation is investigated using a non-return-to-zero (NRZ) bit pattern generator creating an electrical pseudo-random binary sequence (PRBS) on-off-keying (OOK) signal with a word length of $2^{7}-1$ bits. The electrical signal, applied to the not $50 \Omega$ impedance matched device, is amplified and via a biastee superimposed to a drive current of $165 \mathrm{~mA}$. The swing amplitude is about $1.5 \mathrm{~V}$. For eye diagram and bit-error ratio (BER) measurements, we used a back-to-back (B2B) configuration with direct detection. Thus, the receiver consists only of a variable optical attenuator with an optical power meter and a $50 \mathrm{GHz}$ photo diode with an electrical post amplifier. For the eye diagrams, a $50 \mathrm{GHz}$ sampling oscilloscope and for BER curves an error analyzer (EA) were used. B2B largesignal measurements lead to clearly open eye diagrams up to $15 \mathrm{~Gb} / \mathrm{s}$ as depicted in Figure 3(b). At $15 \mathrm{~Gb} / \mathrm{s}, 12.5 \mathrm{~Gb} / \mathrm{s}$, $10 \mathrm{~Gb} / \mathrm{s}$, and 7.5 Gb/s signal-to-noise ratios (SNR) of 2.2, 3.0, 5.4, and 10.7 are determined, respectively. For all bit rates error-free (BER below $10^{-9}$ ) transmission is demonstrated (Figure 3(a)) without error floors. The received optical power at error-free limit are $-5.5 \mathrm{dBm}(7.5 \mathrm{~Gb} / \mathrm{s}),-3.8 \mathrm{dBm}$ $(10 \mathrm{~Gb} / \mathrm{s}),-1.1 \mathrm{dBm}(12.5 \mathrm{~Gb} / \mathrm{s})$, and $3.6 \mathrm{dBm}(15 \mathrm{~Gb} / \mathrm{s})$, respectively. The slight bend in BER curves at higher bit rates

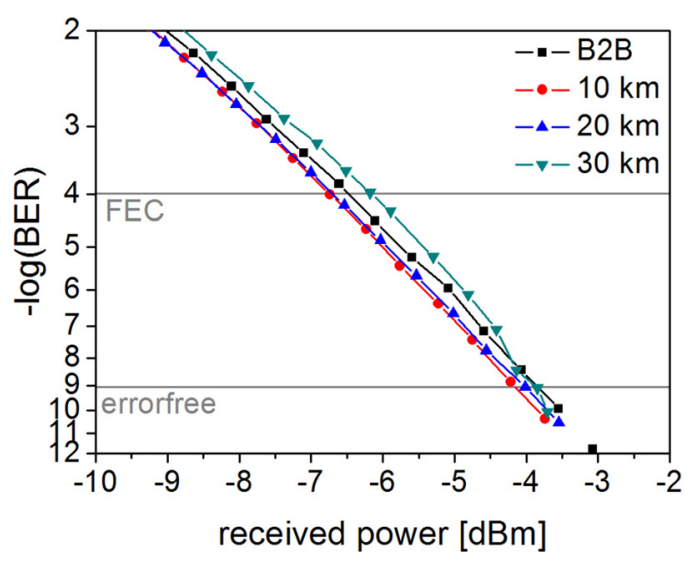

FIG. 4. Bit-error-ratio versus received optical power for $10 \mathrm{~Gb} / \mathrm{s}$ direct data transmission over different fiber lengths up to $30 \mathrm{~km}$. result from lower eye opening and relatively coarse EA threshold accuracy.

In order to proof the suitability for system applications in short-haul WDM systems BERs were recorded for different fiber lengths at $10 \mathrm{~Gb} / \mathrm{s}$ (SNR of 5.4). In Figure 4, the BER curves for B2B and SMF lengths of $10 \mathrm{~km}, 20 \mathrm{~km}$, and $30 \mathrm{~km}$ are shown. Without any kind of optical amplification error-free transmission with no visible error floor is demonstrated for at least $30 \mathrm{~km}$ with a negligible penalty of below $0.5 \mathrm{~dB}$ and corresponding received power of $-4 \mathrm{dBm}$.

To summarize, we have demonstrated high-speed modulation up to $15 \mathrm{~Gb} / \mathrm{s}$ of QD DFB lasers at $1.31 \mu \mathrm{m}$. The purely index-coupled QD DFB lasers exhibit longitudinal and transversal single mode operation up to 5 times the threshold current with a differential efficiency of $27 \%$. The lasers show output power up to $34 \mathrm{~mW}$ and due to p-doping a large temperature stability with a negative characteristic temperature larger than $-130 \mathrm{~K}$ up to $40^{\circ} \mathrm{C}$. Devices processed from a single wafer cover a wavelength range from $1290 \mathrm{~nm}$ to $1310 \mathrm{~nm}$ with a high SMSR of $>58 \mathrm{~dB}$. Errorfree data transmission at a record $15 \mathrm{~Gb} / \mathrm{s}$ at a receiver power of $3.6 \mathrm{dBm}$ in direct detection mode is demonstrated. Furthermore, data transmission across $30 \mathrm{~km}$ of SMF without optical amplification are demonstrated.

This work was supported by the Sonderforschungsbereich 787 of the German Research Council. The authors want to thank A. Sigmund, R. Steingrüber, and M. Möhrle from the FhG Heinrich-Hertz-Institute for assistance with e-beam writing.

\footnotetext{
${ }^{1}$ H. Ghafouri-Shiraz, "Distributed Feedback Laser Diodes and Optical Tunable Filters" (John Wiley \& Sons Ltd., Chichester, 2003), Chap. 4.

${ }^{2}$ L. A. Coldren, S. Corzine, and M. Masanovic, "Diode Lasers and Photonic Integrated Circuits, 2nd Edition" (John Wiley \& Sons, Inc., Hoboken, 2012), p. 484.

${ }^{3}$ R. L. Sellin, C. Ribbat, M. Grundmann, N. N. Ledentsov, and D. Bimberg, Appl. Phys. Lett. 78, 1207 (2001).

${ }^{4}$ O. B. Shchekin and D. G. Deppe, Appl. Phys. Lett. 80, 3277 (2002).

${ }^{5}$ D. O’Brien, S. P. Hegarty, G. Huyet, J. G. McInerney, T. Kettler, M. Laemmlin, D. Bimberg, V. M. Ustinov, A. E. Zhukov, S. S. Mikhrin, and A. R. Kovsh, Electron. Lett. 39, 1819 (2003).

${ }^{6}$ D. Bimberg, N. Kirstaedter, N. N. Ledentsov, Zh. I. Alferov, P. S. Kop'ev, and V. M. Ustinov, IEEE J. Sel. Top. Quantum Electron. 3, 196 (1997).

${ }^{7}$ D. Bimberg, M. Kuntz, and M. Laemmlin, Appl. Phys. A 80, 1179 (2005). ${ }^{8}$ D. Bimberg, Electron. Lett. 44, 168 (2008).

${ }^{9}$ D. Arsenijević, A. Schliwa, H. Schmeckebier, M. Stubenrauch, M. Spiegelberg, D. Bimberg, V. Mikhelashvili, and G. Eisenstein, Appl. Phys. Lett. 104, 181101 (2014).
} 
${ }^{10}$ D. Bimberg, M. Grundmann, N. N. Ledentsov, S. S. Ruvimov, P. Werner, U. Richter, J. Heydenreich, V. M. Ustinov, P. S. Kopev, and Z. I. Alferov, Thin Solid Films 267, 32 (1995).

${ }^{11}$ D. G. Deppe, H. Huang, and O. B. Shchekin, IEEE J. Quantum Electron. 38, 1587 (2002).

${ }^{12}$ H. Su and L. F. Lester, J. Phys. D: Appl. Phys. 38, 2112 (2005).

${ }^{13}$ F. Gerschutz, M. Fischer, J. Koeth, M. Chacinski, R. Schatz, O. Kjebon, A. Kovsh, I. Krestnikov, and A. Forchel, Electron. Lett. 42, 1457 (2006).

${ }^{14}$ K. Goshima, T. Amano, K. Akita, R. Akimoto, T. Sugaya, M. Mori, and K. Komori, Jap. J. Appl. Phys. 48, 050203 (2009).

${ }^{15}$ J. J. Hu, D. Klotzkin, J. S. Huang, X. Y. Sun, and N. Y. Li, IEEE Photonics Technol. Lett. 23, 329 (2011).

${ }^{16}$ K. Takada, Y. Tanaka, T. Matsumoto, M. Ekawa, H. Z. Song, Y. Nakata, M. Yamaguchi, K. Nishi, T. Yamamoto, M. Sugawara, and Y. Arakawa, Electron. Lett. 47, 206 (2011).

${ }^{17}$ A. Ramdane, F. Devaux, N. Souli, D. Delprat, and A. Ougazzaden, IEEE J. Sel. Top. Quantum Electron. 2, 326 (1996).
${ }^{18}$ A. R. Kovsh, A. E. Zhukov, N. A. Maleev, S. S. Mikhrin, V. M. Ustinov, A. F. Tsatsul'nikov, M. V. Maksimov, B. V. Volovik, D. A. Bedarev, Y. M. Shernyakov, E. Y. Kondrat'eva, N. N. Ledentsov, P. S. Kop'ev, Z. I. Alferov, and D. Bimberg, Semiconductors 33, 929 (1999).

${ }^{19}$ A. Stintz, G. T. Liu, H. Li, L. F. Lester, and K. J. Malloy, IEEE Photonics Technol. Lett. 12, 591 (2000).

${ }^{20}$ I. P. Marko, N. F. Masse, S. J. Sweeney, A. D. Andreev, A. R. Adams, N. Hatori, and M. Sugawara, Appl. Phys. Lett. 87, 211114 (2005).

${ }^{21}$ H. Soda, Y. Kotaki, H. Sudo, H. Ishikawa, S. Yamakoshi, and H. Imai, IEEE J. Quantum Electron. 23, 804 (1987).

${ }^{22}$ M. Kuntz, G. Fiol, M. Lämmlin, D. Bimberg, M. G. Thompson, K. T. Tan, C. Marinelli, A. Wonfor, R. Sellin, R. V. Penty, I. H. White, V. M. Ustinov, A. E. Zhukov, Yu. M. Shernyakov, A. R. Kovsh, N. N. Ledentsov, C. Schubert, and V. Marembert, New J. Phys. 6, 181 (2004).

${ }^{23}$ T. Okoshi, K. Kikuchi, and A. Nakayama, Electron. Lett. 16, 630 (1980). 